\title{
In Reply: Vitamin D Status May Explain Some of the Racial Disparities in Rectal Cancer
}

\author{
James R. Nitzkorski, MD ${ }^{1}$, Alliric I. Willis, $\mathrm{MD}^{2}$, Donna Nick, $\mathrm{CTR}^{3}$, Fang Zhu, $\mathrm{PhD}^{4}$, Jeffrey M. Farma, $\mathrm{MD}^{5}$, and \\ Elin R. Sigurdson, MD, $\mathbf{P h D}^{5}$ \\ ${ }^{1}$ Department of Surgery, Vassar Brothers Medical Center, Poughkeepsie, NY; ${ }^{2}$ Department of Surgery, Jefferson \\ University Hospital, Philadelphia, PA; ${ }^{3}$ Department of Health Information, Temple University School of Medicine, \\ Philadelphia, PA; ${ }^{4}$ Department of Biostatistics, Fox Chase Cancer Center, Philadelphia, PA; ${ }^{5}$ Department of Surgery, Fox \\ Chase Cancer Center, Philadelphia, PA
}

The authors would like to thank Dr. Grant for his insightful comments on our recently published rectal cancer disparity paper. ${ }^{1}$ The association of serum 25-hydroxyvitamin D [25(OH)D] levels and cancer is interesting; ${ }^{2,3}$ however, many papers, including the mentioned studies, look at colorectal cancer as an heterogeneous group rather than isolating rectal cancer as a biologically unique disease. The referenced cohort study included 304 patients with colorectal cancer, but unfortunately only approximately $25 \%$ had rectal cancer. ${ }^{3}$ This distinction is important when considering variables associated with rectal cancer survival, especially when considering that the biological response to multimodality therapy is variable. Although most patients with locally advanced rectal cancer respond favorably, or even completely, after preoperative chemoradiation, some patients respond poorly. Predicting response to preoperative chemoradiation remains impossible without an improved understanding of biomarkers. It would indeed be interesting to examine the relationship of serum $25(\mathrm{OH}) \mathrm{D}$ levels before and after chemoradiation to discover any potential relationship to tumor response.

\section{REFERENCES}

1. Nitzkorski JR, Willis AI, Nick D, Zhu F, Farma JM, Sigurdson ER. Association of race andsocioeconomic status and outcomes of patients with rectal cancer. Ann Surg Oncol. 2013;20:1142-7.

2. Grant WB, Peiris AN. Differences in vitamin D status may account for unexplained disparities in cancer survival rates between African and White Americans. Dermatoendocrinology. 2012;4: $85-94$

3. Ng K, Meyerhardt JA, Wu K, Feskanich D, Hollis BW, Giovannucci EL, et al. Circulating 25-hydroxyvitamin D levels and survival in patients with colorectal cancer. J Clin Oncol. 2008;26:2984-91.
(C) Society of Surgical Oncology 2017

First Received: 31 October 2017;

Published Online: 1 December 2017

J. R. Nitzkorski, MD

e-mail: jnitzkor@health-quest.org 